\title{
Self-titration by cigarette smokers
}

\author{
HEATHER ASHTON, R STEPNEY, J W THOMPSON
}

titrate upwards from low-nicotine cigarettes is extremely limited. Some of the equivocal results from these studies may have occurred because the cigarettes used were drawn from the extremes of available nicotine yield ${ }^{4}$ (reducing the relevance of

\section{Summary and conclusions}

An 11-week crossover study was carried out in which 12 subjects smoked high-nicotine (1.84 $\mathrm{mg}$ standard yield) and low-nicotine (0.6 mg) cigarettes after an initial period of smoking their usual brands with a medium-nicotine yield (mean $1.4 \mathrm{mg}$ ). Plasma and urine nicotine concentrations, carboxyhaemoglobin (COHb) concentration, puffing behaviour, 24-hour cigarette consumption, and butt nicotine content were measured. The changes in plasma nicotine and blood $\mathrm{COHb}$ concentrations showed that the smokers compensated for about two-thirds of the difference in standard yields when switched to either high- or low-nicotine cigarettes. Thus, compared with the medium-nicotine brand, the intake of nicotine and carbon monoxide was only about $10 \%$ higher when subjects smoked the high-nicotine cigarettes, which had a standard yield $30-40 \%$ higher than the medium brands; and only about $15 \%$ lower when they smoked the lownicotine cigarettes, which had a standard yield about $\mathbf{5 0 \%}$ lower than the medium brands. Butt nicotine content and urine nicotine concentrations followed a similar pattern. Changes in puffing behaviour and in 24-hour cigarette consumption were only slight.

The results show clear evidence of both upward and downward self-titration of nicotine and carbon monoxide (and tar) intakes when smokers change to cigarettes with standard yields that differ over the range studied.

\section{Introduction}

Do smokers adjust their nicotine intake to some habitual optimal level when smoking cigarettes of different strengths? Evidence concerning this self-titration hypothesis is conflicting, but a clear answer is important in planning and evaluating the effects of safer-smoking strategies in which smokers are advised to switch to cigarettes of decreased nicotine, tar, and carbon monoxide delivery. ${ }^{1}$

Several short-term studies have shown that smokers make apparently compensatory changes in smoking behaviour when the nicotine (and tar) yield of their cigarettes is changed. ${ }^{2-6}$ At least one long-term study, ${ }^{7}$ however, suggests that smokers can adapt without compensation to a moderate reduction in nicotine yield. Some work indicates that self-titration is often only moderate or slight, ${ }^{8}{ }^{9}$ and Russell $e t$ al ${ }^{5}$ found that, although smokers seem to have efficient guards against taking higher than usual doses of nicotine, so that they show downward titration when presented with high-nicotine cigarettes, their ability to

\footnotetext{
Clinical Psychopharmacology Unit, Department of Pharmacological Sciences, University of Newcastle upon Tyne, Newcastle upon Tyne NE2 4AB

HEATHER ASHTON, DM, FRCP, senior lecturer in psychopharmacology and consultant clinical pharmacologist

R STEPNEY, MA, MSC, junior research associate (present address: department of medicine, University of Cambridge Clinical School)

J W THOMPSON, PHD, MRCP, professor of pharmacology and consultant clinical pharmacologist, Newcastle Area Health Authority (Teaching)
} the findings to the kind of brand-switching likely to occur among the general smoking population), or because the different brands were not presented in the balanced order necessary to allow for effects due to time and habituation to the experiment. ${ }^{6}$ In addition, workers have often used only a few measures of smoke intake and have tended to consider smoking over a period of time too short to allow for adaptation to different brands.

Thus in the present experiment we used a balanced crossover design in which smokers switched between moderately highnicotine $(1.84 \mathrm{mg})$ and moderately low-nicotine $(0.6 \mathrm{mg})$ cigarettes after a preliminary period on their usual intermediatestrength $(1.4 \mathrm{mg})$ cigarettes. The advantages of this study were that (1) smokers were followed up for 11 weeks, (2) information was obtained on both 24-hour cigarette consumption and cigarettes smoked in the laboratory, and (3) several measures of nicotine intake were taken, including plasma and urine nicotine concentrations and butt analysis, as well as blood carboxyhaemoglobin $(\mathrm{COHb})$ concentrations and smoking behaviour.

\section{Subjects and methods}

Twelve volunteers (six men, six women; mean age 28.6 years) participated in the experiment. All had smoked middle-tar or mediumnicotine cigarettes (mean self-reported consumption 158 cigarettes per week, range 35-250) for at least two years, and all inhaled. They were examined clinically and passed fit before entry into the study. They received expenses for each laboratory attendance, and cigarettes were provided free. The subjects agreed to smoke only cigarettes obtained from the laboratory and to record all cigarettes given away; unsmoked cigarettes were returned each week. They were told that they would be supplied with cigarettes, initially of their own brand, but no mention was made of altering the strength or nicotine yield of the experimental cigarettes, which were provided in similar unbranded packs.

Table I shows the experimental procedure. For the first three weeks

TABLE I-Experimental procedure, showing type of cigarette smoked each week

\begin{tabular}{|c|c|c|c|}
\hline Weeks & Attendance No & Group 1 & Group 2 \\
\hline$\frac{1}{2-3}$ & 2,3 & \multicolumn{2}{|c|}{$\begin{array}{l}\text { Usual cigarette brand (paid for by subject) } \\
\text { Usual cigarette brand (free) }\end{array}$} \\
\hline $\begin{array}{l}4-5 \\
6-8\end{array}$ & 4,5 & $\begin{array}{l}\text { High-nicotine brand } \\
\text { High-nicotine brand }\end{array}$ & $\begin{array}{l}\text { Low-nicotine brand } \\
\text { Low-nicotine brand }\end{array}$ \\
\hline $\begin{array}{c}0-0 \\
9 \\
10-11\end{array}$ & $\begin{array}{c}6 \\
7,8\end{array}$ & $\begin{array}{l}\text { High-nicotine brand } \\
\text { Low-nicotine brand }\end{array}$ & $\begin{array}{l}\text { Low-nicotine brand } \\
\text { High-nicotine brand }\end{array}$ \\
\hline
\end{tabular}

subjects smoked their own brands and attended the laboratory at weekly intervals. The first attendance familiarised subjects with the laboratory, and data collected then are not included in the results. The subjects were then divided into two groups, matched for age, sex, and cigarette consumption. Group 1 smoked high-nicotine $(1.84 \mathrm{mg})$ cigarettes for six weeks (attending the laboratory on weeks 4,5 , and 9) then low-nicotine $(0.6 \mathrm{mg})$ cigarettes for two weeks (and two attendances). Group 2 followed a similar sequence but smoked lownicotine cigarettes for six weeks followed by high-nicotine cigarettes for two weeks. Subjects always attended the laboratory in the morning and at the same time of day, and the number of cigarettes they smoked on the morning of attendance was not restricted.

Weekly cigarette consumption-The number of cigarettes smoked 
each week was calculated by subtracting the numbers returned and given away from the total number given to each subject.

Puffing behaviour-On each laboratory attendance subjects smoked a single cigarette while their smoking behaviour was observed through a one-way glass screen. Puffing behaviour was recorded by an observer, who pressed a button for the duration of each cigarette "glow" and signalled the lighting and extinguishing of the cigarette. The pushbutton activated an event marker, and from the record a puffing profile was constructed, showing the time taken to smoke the cigarette, the total number of puffs, and the temporal pattern and duration of each puff. From this information the per cent puff time-that is, the total time spent puffing expressed as a percentage of the total time the cigarette was lit-was calculated.

Butt analysis - The filter tips from cigarettes smoked in the laboratory and from all cigarettes smoked over the 24 hours before each laboratory attendance were collected and analysed for nicotine content, establishing a measure of mouth nicotine exposure. (Butt analysis kindly arranged by Dr R E Thornton, British-American Tobacco Co Ltd.)

Plasma nicotine concentration-At the start of each laboratory attendance a butterfly needle was inserted into an antecubital vein. The experimenter taking the blood samples sat beside the subject's arm, behind a curtain screening it and the experimenter from view. The needle and its attached tubing (total dead space $1 \mathrm{ml}$ ) were kept patent with heparinised saline, but to avoid dilution of blood samples the dead space and $2 \mathrm{ml}$ of blood were withdrawn and discarded before a sample was collected for analysis. A presmoking blood sample was taken immediately before the subject started to smoke a cigarette. The subject smoked in his normal manner (while reading light literature) but signalled when about to take his last puff. A postsmoking blood sample was withdrawn immediately this last puff was completed. In each case $20 \mathrm{ml}$ of blood was collected in a cold, heparinised syringe. The plasm was separated at once and stored at $-20^{\circ} \mathrm{C}$ until assayed for nicotine. The assays were carried out by $\mathrm{Dr} C$ Feyerabend using a gas chromatographic method. ${ }^{11}$

Urine nicotine concentration-Subjects collected all urine for 24 hours before each laboratory attendance; aliquots were assayed for nicotine and cotinine by a gas chromatographic method. ${ }^{11}$

Blood $\mathrm{COHb}-\mathrm{COHb}$ was measured in the presmoking and postsmoking blood samples, immediately on collection, using an IL182 $\mathrm{CO}$-oximeter (Instrumentation Lab Inc).

Other measures-Heart rate, fingertip temperature, subjective rating scores, and personality characteristics were also measured. These results and their correlations with each other and with the data given here will be presented in another report.

Analysis of results - The mean values of all measures for the subjects' own brand of cigarettes were based on attendances 2 and 3 (see table I). For high-nicotine cigarettes the mean results were based on attendances 4 and 5 (group 1 ) and 7 and 8 (group 2). The mean results for low-nicotine cigarettes were estimated from attendances 4 and 5 (group 2) and 7 and 8 (group 1). The results from attendance 6 are not included, but for both groups were not significantly different from those from attendances 4 and 5 .

\section{Results}

Table II summarises the results.

Mouth nicotine intake-As determined by butt analysis, mouth nicotine intake per cigarette was greater with the high-nicotine cigarettes than with the subjects' usual brands, and greater with their usual brands than with the low-nicotine cigarettes. The difference in mouth nicotine intake between the high- and low-nicotine brands was highly significant both inside and outside the laboratory. The betweenbrand differences in observed intake, however, were considerably less than would have been expected on the basis of the yields obtained when the cigarettes were machine-smoked to the standard specifications (of puff volume, duration, and frequency) laid down by the UK Government Chemist. The machine yield of nicotine of the low-nicotine cigarettes was only one-third that of the high-nicotine cigarettes (low $0.6 \mathrm{mg}$, high $1.84 \mathrm{mg}$; table II), so that the "expected" yield from the low-nicotine cigarettes was $32.6 \%$ of that of the high-nicotine brand. But the observed yield from the low-nicotine cigarettes was $59 \%$ of that of the high-nicotine cigarettes when smoked in the laboratory (low $1.18 \mathrm{mg}$, high $2.0 \mathrm{mg}$ ) and $63 \%$ for the 24-hour period (low $0.88 \mathrm{mg}$, high $1.4 \mathrm{mg}$ ). A similar picture emerged when the mouth nicotine intake for the low-nicotine cigarettes was compared with that for the subjects' usual brands. Instead of an expected $43 \%$, subjects obtained from the low-nicotine cigarettes $87 \%$ of their usual intake when smoking in the laboratory and $96^{\circ}{ }_{0}$ over the 24 -hour periods of smoking. The total mouth nicotine intake over 24 hours (intake per cigarette $\times$ number smoked in 24 hours) from low-nicotine cigarettes actually exceeded that from the subjects' usual brand $(105 \%)$. With cigarettes of all three types, subjects obtained a significantly higher mouth nicotine intake from cigarettes smoked in the laboratory than on average from cigarettes smoked outside the laboratory (own brands $P<0.001$; high-nicotine cigarettes $P<0.005$; low-nicotine cigarettes $P<0.01$ )

Plasma nicotine concentrations-The presmoking plasma nicotine concentration and the increase in concentration after smoking a single cigarette tended to fall with the decreasing standard nicotine yield of the cigarettes smoked (fig 1). Between-brand differences, however, were again much less than the standard nicotine yields would suggest. Taking the rise in blood nicotine concentration with subjects' usual brands as a baseline, a rise in concentration of $50.3 \mathrm{nmol} / 1(8.1 \mathrm{ng} / \mathrm{ml})$ would be expected if smokers smoked the low-nicotine brand in the same way as they smoked the medium-nicotine cigarettes. The rise actually observed was $83.8 \mathrm{nmol} / 1(13.6 \mathrm{ng} / \mathrm{ml})$. In the case of the

TABLE II-Mean $\pm S E$ of mean intakes of nicotine and carbon monoxide, and smoking behaviour according to brand in 12 subjects studied

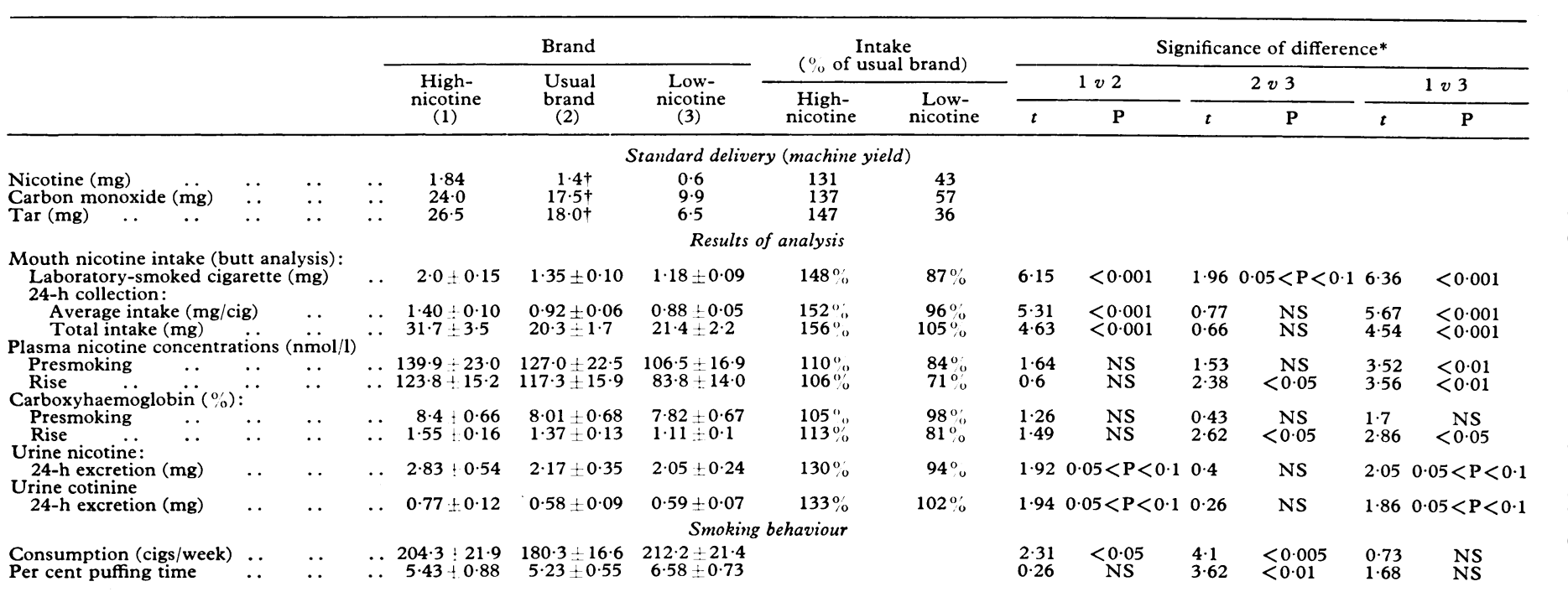

*Student's two-tailed $t$ test.

†Mean value.

Conversion: SI to traditional units-Plasma nicotine: $1 \mathrm{nmol} / 1 \approx 0 \cdot 16 \mathrm{ng} / \mathrm{ml}$ 
high-nicotine brand a similar compensatory process appeared to operate, but in the reverse direction. Thus the predicted rise of $154 \mathrm{nmol} / 1(25.0 \mathrm{ng} / \mathrm{ml})$ corresponded to an observed rise of only $123.8 \mathrm{nmol} / \mathrm{l}(20 \cdot 1 \mathrm{ng} / \mathrm{ml})$. Presmoking nicotine concentrations (providing an indication of intake over a longer period) suggested that subjects compensated even more fully for the reduced standard yield of the low-nicotine brand. The observed presmoking value of 106.5 $\mathrm{nmol} / 1(17.3 \mathrm{ng} / \mathrm{ml})$ was almost exactly double that expected on the basis of standard deliveries $(54.4 \mathrm{nmol} / 1(8.8 \mathrm{ng} / \mathrm{ml}))$.

$\mathrm{COHb}$ concentration-Despite widely differing standard yields of carbon monoxide, no significant differences were found between brands in presmoking $\mathrm{COHb}$ concentrations. The rise in $\mathrm{COHb}$ values over the period of smoking was significantly smaller with the lownicotine cigarettes than with either the high- or medium-nicotine brands. Observed differences between the brands, however, were again much less than would be expected on the basis of standard carbon monoxide yield (see table II and fig 1). While the expected carbon monoxide delivery of the low-nicotine brand was only $41 \%$ of that of the high-nicotine brand (low $9.9 \mathrm{mg}$; high $24.0 \mathrm{mg}$ ), the actual rise over smoking was $72 \%$ (low $1.11 \%$, high $1.55 \%$ ). When the lownicotine brand was compared with the smokers' usual cigarettes, the expected rise in $\mathrm{COHb}$ of $57 \%$ corresponded to an actual rise of $71 \%$.

Urine nicotine and cotinine concentrations-Values for the 24-hour
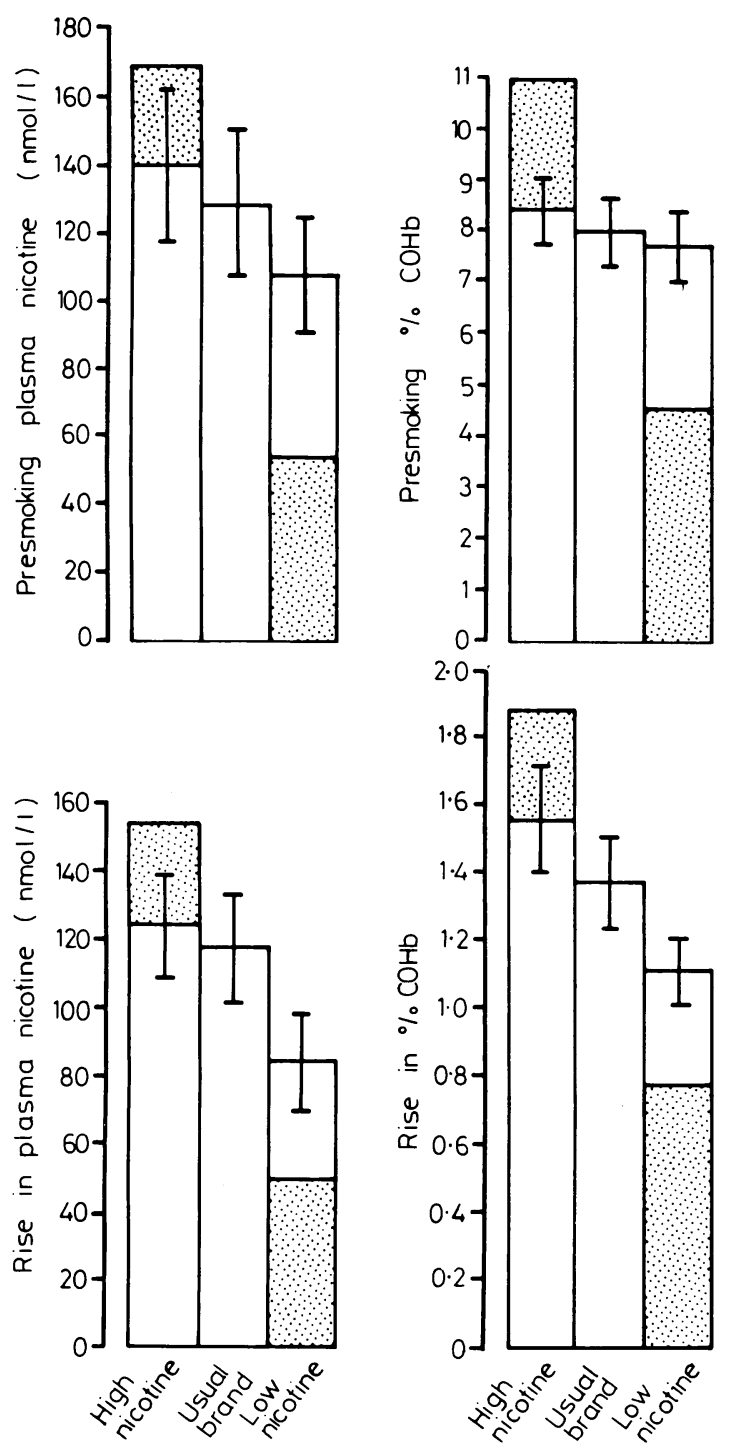

FIG 1-Mean \pm SE of mean plasma nicotine concentration and per cent blood carboxyhaemoglobin ( $\mathrm{COHb}$ ) according to cigarette brand in 12 subjects studied. Top: presmoking concentrations; bottom : rise in concentrations with smoking. Stippled areas indicate concentrations expected on basis of standard yields.

Conversion: SI to traditional units-Plasma nicotine: $1 \mathrm{nmol} / \mathrm{l} \approx 0 \cdot 16 \mathrm{ng} / \mathrm{ml}$ excretion of nicotine indicated differences of marginal significance between brands. While smoking high-nicotine cigarettes, with a nicotine yield $31^{\circ}$, greater than that of their usual brands, subjects excreted $30 \%$ more nicotine. With the low-nicotine cigarettes, however, which had a nicotine yield $43 \%$ of that of the usual brands, the 24-hour excretion was $94 \%$. Urine cotinine excretion followed a similar pattern.

Smoking behaviour-The percentage puffing time for laboratorysmoked cigarettes and weekly cigarette consumption were slightly greater with low-nicotine cigarettes than with the high- or mediumnicotine brands. These values were also slightly higher with the highnicotine cigarettes than with the subjects' usual brands.

\section{Discussion}

Analysis of plasma nicotine and blood $\mathrm{COHb}$ concentrations, the most direct measures of the intake of smoke constituents, provides clear and consistent evidence that habitual smokers of middle-tar or medium-nicotine cigarettes adjust their intake of smoke constituents when smoking brands of a different standard nicotine yield to obtain a greater than expected intake from "weaker" cigarettes and a less than expected intake from "stronger" cigarettes. Figure 2, however, shows that the extent to which the actual intake of nicotine is equalised across brands varies greatly between subjects, and, even considering mean values for the group, compensation for standard delivery differences is obviously incomplete.

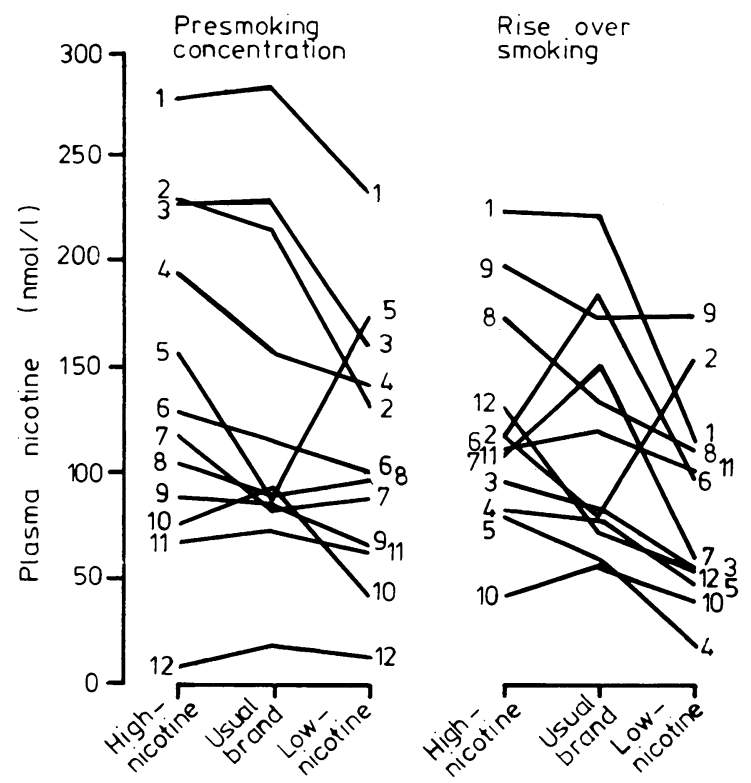

FIG 2-Presmoking plasma nicotine concentrations and rise in concentrations over smoking by cigarette brand in 12 subjects studied. (Each point represents mean value for two attendances.)

Conversion: SI to traditional units-Plasma nicotine: $1 \mathrm{nmol} / 1 \approx$ $0.16 \mathrm{ng} / \mathrm{ml}$.

Nevertheless, the changes in plasma nicotine and blood $\mathrm{COHb}$ concentrations show that the smokers compensated for about two-thirds of the difference in standard yields when switched from medium-nicotine to high- or low-nicotine brands. Thus, if the information from the various plasma nicotine and blood $\mathrm{COHb}$ measures is considered together, the intakes of nicotine and carbon monoxide were about $10 \%$ higher than with the usual brand when the subjects smoked the brand yielding $30-40 \%$ more nicotine and carbon monoxide and roughly $15 \%$ lower than with the usual brand when the subjects smoked the brand yielding around $50 \%$ less nicotine and carbon monoxide. Evidence from the other measures less directly related to the quantities of nicotine and carbon monoxide actually absorbed by the smokers-that is, butt nicotine estimations (which do not 
allow for differences in inhalation) and urinary nicotine excretion rate-broadly support this conclusion.

The relevance of standard nicotine and tar deliveries to actual smoking has been questioned. ${ }^{12}$ The relation between nicotine deliveries actually obtained by smokers in the present study and

TABLE III-Mouth nicotine intake estimated by butt analysis and expressed as percentage of delivery expected from standard (machine) yields

\begin{tabular}{cccc}
\hline Cigarette brand & & $\begin{array}{c}\text { Cigarette smoked } \\
\text { in laboratory }\end{array}$ & $\begin{array}{c}\text { 24-hour collection } \\
\text { (mean per cigarette) }\end{array}$ \\
\hline $\begin{array}{l}\text { High-nicotine } \\
\text { Usual brand (medium-nicotine) }\end{array}$ & 109 & 76 \\
Low-nicotine & $\ldots$ & 96 & 96 \\
\end{tabular}

those expected on the basis of the standardised smoking of a machine is therefore of interest (table III). With high- and medium-nicotine brands smoked in the laboratory the predicted yields were close to those actually observed. The predicted yields, however, considerably overestimated the average nicotine yield of both types of cigarette over 24-hour periods of presumably more-normal smoking outside the laboratory. This finding suggests that the criteria used to derive the standard yields of high- and medium-nicotine cigarettes overestimate the intensity with which these cigarettes are actually smoked. Conversely, the same criteria underestimate the nicotine intake from low-nicotine cigarettes, both inside and outside the laboratory.

The changes in smoking behaviour which result in this degree of compensation appear to be complex, since in these subjects nicotine yield was not associated with either per cent puffing time or 24-hour consumption. Changes in inhalation or strength of draw on the cigarette, or both, may have been among the many variables implicated. It is tempting to conjecture that the powerful self-regulation of nicotine intake shown by these results are brought about by central nervous mechanisms that may well include chemoreceptors.

We are grateful to $\mathrm{Mr} \mathrm{E}$ Meredith for carrying out the urine nicotine and cotinine estimations, Mr V R Marsh and Mr G Nixon for technical help, Mrs V Wright for secretarial help, and the Tobacco Research Council for generous financial help.

\section{References}

${ }^{1}$ Health Departments of the UK, Tar and Nicotine Yields of Cigarettes. London, DHSS, 1979.

${ }^{2}$ Ashton, H, and Watson, D W, British Medical fournal, 1970, 3, 679.

${ }^{3}$ Frith, C D, Psychopharmacologia, 1971, 19, 188.

4 Russell, M A H, et al, British Medical fournal, 1973, 4, 512.

${ }^{5}$ Russell, M A H, et al, British Medical fournal, 1975, 2, 414.

6 Turner, J A McM, Sillett, R W, and Ball, K P, Lancet, 1974, 2, 737.

${ }^{7}$ Freedman, S, and Fletcher, C M, British Medical fournal, 1976, 1, 1427.

${ }^{8}$ Kozlowski, L T, Jarvik, M E, and Gritz, E R, Clinical Pharmacology and Therapeutics, 1975, 17, 93.

9 Schachter, S, Fournal of Experimental Psychology: General, 1977, 106, 5.

${ }^{10}$ Feyerabend, C, and Russell, M A H, Fournal of Pharmacy and Pharmaco$\log y, 1979, \mathbf{3 1}, 73$.

${ }^{11}$ Beckett, A H, and Triggs, E J, Nature, 1966, 211, 1415.

12 Green, S J, in Smoking Behaviour: Physiological and Psychological In fluences, ed R E Thornton. Edinburgh, Churchill Livingstone, 1978.

(Accepied 28 fune 1979)

\title{
Adverse reactions to frusemide in hospital inpatients
}

\author{
JULIA LOWE, JANE GRAY, D A HENRY, D H LAWSON
}

British Medical fournal, 1979, 2, 360-362

\section{Summary and conclusions}

Out of 2580 medical inpatients included in a drugsurveillance programme, $585(22.7 \%)$ were treated with frusemide. Of these, $123(21 \cdot 0 \%)$ had a total of 177 adverse reactions. The most common were hypovolaemia (85 cases), hyperuricaemia (54), and hypokalaemia (21). Most reactions were mild, and only three patients had potentially life-threatening effects. The incidence of adverse reactions increased significantly with daily dose, occurring in 47 patients $(13.5 \%$ ) given up to $40 \mathrm{mg}, 42$ $(26.3 \%)$ given up to $80 \mathrm{mg}$, and $34(43.6 \%)$ given over $80 \mathrm{mg}(\mathbf{P}<0.001)$. There was no clear association between side effects and a raised blood urea concentration on admission, confirming that treatment with frusemide is not more hazardous in patients with renal failure.

Drug Surveillance Programme, Royal Infirmary, Glasgow

JULIA LOWE, MB, MRCP, medical registrar (present address: Medical School, University of Nottingham, Nottingham NG7 2RD)

JANE GRAY, MB, CHB, research assistant

D A HENRY, MB, MRCP, medical registrar (now lecturer in therapeutics, University of Nottingham, City Hospital, Nottingham NG5 1PB)

D H LAWSON, MD, FRCP, consultant physician
Frusemide is a safe and highly effective diuretic. Nevertheless, in view of the potential seriousness of volume depletion, dosage should probably begin at 20 rather than $40 \mathrm{mg}$ daily.

\section{Introduction}

Frusemide became available for use in the UK in 1964 and rapidly became the most widely used diuretic. Undesired effects include electrolyte disturbance, volume depletion, and hyperuricaemia, ${ }^{1}$ but their true incidence is unknown. We describe the reactions noted in 585 consecutive recipients of frusemide who participated in a drug-surveillance programme.

\section{Patients and methods}

Consecutive patients admitted to general medical wards in the Western Infirmary and Stobhill General Hospital, Glasgow, participated in the study. The methods used were similar to those of the Boston Collaborative Drug Surveillance Programme, of which our programme is an offshoot. ${ }^{2}$ Specially trained nurses (monitors) use standardised self-coding data sheets to record demographic and diagnostic information on admission. When drugs are prescribed a detailed record is kept of the starting and stopping indications, dose given, and presence or absence of any undesired or unintended effect (the adverse reaction). When a suspected adverse reaction is reported 